\title{
Oficinas Pedagógicas na Formação Inicial de Professores de Ciências e Biologia: Espaço para Formação Intercultural
}

\section{Pedagogical Workshops in the Initial Training of Science and Biology Teachers: Space for Intercultural Training}

Daís de Souza Rédua'

Danilo Seithi Kato ${ }^{2}$

'Universidade Federal do Triângulo Mineiro (UFTM), Instituto de Ciências Exatas, Naturais e Educação (ICENE), Uberaba, MG, Brasil. Autora correspondente: lais.redua@hotmail.com

2Universidade Federal do Triângulo Mineiro (UFMT), Programa de Pós-graduação em Educação, Uberaba, MG, Brasil.

Resumo: Este trabalho consiste em analisar as interações do sujeito na posição de futuro professor de ciências e biologia no desenvolvimento de oficinas pedagógicas como espaços de formação intercultural. A oficina pedagógica foi construída a partir de observações nos cursos de Educação do Campo e Ciências Biológicas, contou com cinco situações-problemas e foi desenvolvida em disciplinas da área pedagógica desses cursos. Com a materialidade dos dados a análise do discurso evidenciou três momentos principais de discussão: (i) Posicionamentos performáticos: parâmetros científicos que validam outras culturas; (ii) Tensões nas posições de enunciação: frestas do etnocentrismo no ensino de ciências e formação docente; (iii) Mobilização dos saberes relacionados aos contextos socioculturais e identidades dos sujeitos: deslocamentos das posições enunciativas. As situações-problemas possibilitaram a formação de pontes e cruzamentos interculturais e, a partir desse formato, repensar questões inerentes à existência desses sujeitos por meio das frestas que dissolveram a performance esperada e reproduzida em uma perspectiva etnocêntrica.

Palavras-chave: Ensino de biologia; Formação intercultural; Formação inicial de professores; Oficinas pedagógicas.

Abstract: This article consists of analyzing the interactions of the subject in the position of future teacher of sciences and biology in the development of pedagogical workshops as spaces of intercultural formation. The pedagogical workshop was built from observations in the courses of Field Education and Biological Sciences, had five problem situations and was developed in disciplines of the pedagogical area of these courses. With the materiality of the data, the discourse analysis revealed three main moments of discussion: (i) Performative positioning: scientific parameters that validate other cultures; (ii) Tensions in enunciation positions: cracks in ethnocentrism in science teaching and teacher training; (iii) Mobilization of the knowledge related to the sociocultural contexts and identities of the subjects: displacements of enunciative positions. The problem situations allowed the formation of intercultural bridges and crosses from this format to rethink issues inherent to the existence of these subjects from cracks that dissolve the performance expected and reproduced in an ethnocentric perspective.

Keywords: Biology teaching; Intercultural training; Initial training of teachers; Pedagogical workshop.

Recebido em: 21/01/2019

Aprovado em: 24/07/2019 


\section{Introdução}

Nas discussões sobre estratégias de ensino e aprendizagem a oficina pedagógica é uma modalidade que permite a mobilização de conhecimentos a partir das interações entre os participantes. Candau (1995) discute que a utilização desta estratégia proporciona espaço de aproximação, comunicação, participação da produção social de objetos e construções de conhecimentos. No mesmo âmbito de discussão, Anastasiou e Alvez (2004, p. 49) denominam essa metodologia como "lugar de pensar, descobrir, reinventar, criar e recriar, favorecido pela forma horizontal na qual a relação humana se dá". Essa estratégia busca, comumente, contrapor o modelo tradicional de transmissão e memorização de conteúdo mudando a dinâmica hierarquizada, postulada neste modelo, no que se refere às relações cognitivas entre os participantes e objetos de conhecimento no processo (CHARLOT, 2008).

Candau (1995), Anastasiou e Alvez (2004) apresentam resultados de pesquisas sobre estratégias de ensino que problematizam a oficina pedagógica com potenciais como um espaço de reinventar, construir e produzir com projeções para as questões sociais, integrando pontos importantes da função do ensino. Quando se pensa nesta abordagem dentro do ensino de Ciências e Biologia, há uma facilidade em subverter a real intenção da oficina pedagógica, pois há em vigor a rigidez das ciências naturais em relação à passagem dos conteúdos acumulados historicamente, considerando que conteúdos escolares transmitidos oralmente em aulas expositivas é conteúdo aprendido. Essa concepção concebe a inteligência do homem apenas para armazenar várias informações (CHARLOT, 2008).

O ensino tradicional emerge a partir da supervalorização da ciência moderna difundida socialmente, que por sua vez, sedia a perspectiva positivista da educação. Tem, portanto, como parâmetro premissas racionais etnocêntricas, isto é, os produtos da ciência como a única e verdadeira visão de compreender fenômenos, sendo ela o único conhecimento com método de comprovação fidedigna (SANTOS, 1987). Nesse sentido, pensar a estrutura da disciplina e formação em ciências naturais, como a ciências e biologia, encaixa-se nas lógicas empíricas das ciências naturais que vem do racionalismo cartesiano e empirismo baconiano a qual é base da ciência moderna (SANTOS, 1987). A estrutura prescritiva de uma racionalidade etnocêntrica no desenvolvimento formativo ocasiona ruptura do acervo histórico, social, cultural, político, ambiental e econômico em prol de corresponder a sistematizações de pensamento por uma única interpretação. Ou seja, o que foi dissociado em matérias ou disciplinas de ciências e biologia dentro da estrutura escolar desvincula os conteúdos e propostas do contexto dos alunos, não levando em consideração a vida fora da escola nem que essas disciplinas remetam à vida de fato..

Considerando este argumento, a utilização das diferentes estratégias didáticas como, por exemplo, a oficina pedagógica, pode trazer uma perspectiva de ensinar que ainda prioriza essa estrutura racionalizada de desenvolvê-la nos processos de ensino. Sendo então colocada com o mesmo princípio de aplicações dessa transmissão e memorização científica tradicionalista. Contudo para que a liberdade, participação e produção social sejam de fato oportunizadas, como citado por Candau (1995) e Anastasiou e Alvez (2004), não basta apenas utilizar da estratégia da oficina pedagógica, mas é preciso mobilizar outras concepções que não sejam somente da ciência moderna. 
Ao pensar em estratégias que priorizam a liberdade de discutir e conhecer sobre as múltiplas construções de saberes, os juízos de valores estabelecidos socialmente podem ser desconstruídos de forma a exercitar a construção identitária dos sujeitos e suas relações com a alteridade. A alteridade concerne na compreensão e constituição dos indivíduos na relação como outro. Nessa inter-relaçãoambosse constroem enquanto sujeitos, ampliando as visões de mund ofrentea essa relação, secolocando no lugar do outro pela alteridade doeu(BAKHTIN, 2014).

Assumindo, então, a pluralidade étnica e cultural nos processos educativos a premissa intercultural crítica, associada ao pressuposto teórico sociocultural, busca o princípio de cruzamento de fronteiras culturais, pela alteridade, como forma de compreender a aprendizagem. Assim, a demanda pela horizontalização das relações coloca cosmovisões (visões de mundo) distintas em contato, estabelecendo fronteiras identitárias configuradas pela percepção da diferença, mas sem hierarquias ou subalternizações (WALSH, 2005, 2010). Em outras palavras, os processos de formação deveriam considerar os conteúdos científicos escolares como meios e não como fins em si mesmos. Dessa forma o processo educativo estará vinculado a percepção do eu frente a um outro por vias das diferenças culturais que mobilizam tal percepção e não somente a memorização da informação científica por si.

O que se pretende organizar neste ponto é que o ato educativo deve almejar o movimento discursivo para que possa estabelecer e cruzar fronteiras culturais. Assim, a oficina pedagógica pode ser pensada como momento que pontue a diferença pela própria fronteira cultural daquilo que é a ciência escolarizada e aquilo que é próprio do conhecimento cotidiano. Portanto, para estes momentos de formação é preciso compreender termos e memorizar dispositivos de pensamento. Mas, o intuito central é desnaturalizar, por uma formação intercultural, o que provém de uma racionalidade científica compreendida como verdade absoluta. Isto é, aprender ciência pela diferença cultural, pela percepção das fronteiras entre as culturas que são construídas em diferentes racionalizações, pode ser propiciado pelo olhar e por estratégias com viés intercultural de formar professores.

A relação hegemônica da ciência moderna que é distanciada das realidades socio-históricas e socioculturais existentes, aponta para a formação de professores como projeções mais concretas de mobilizações da compreensão desses artefatos pelas construções e movimentos discursivos concernentes de cosmovisões. Sem que relações de poder passem como uma imposição de apropriação dentro da formação resultando na reprodução discursiva que colaboram na manutenção das desigualdades socioculturais e socioeconômicas por vias epistêmicas em defesa de um único saber legítimo. Os processos de ensino e aprendizagem em um contexto latino-americano, e, portanto, historicamente colonizado, precisam ser concebidos além da noção de tolerância com as diversas manifestações culturais. Sendo então a partir de diálogos interculturais provindos de diferentes formas de construção de conhecimento visando a apropriação do conhecimento científico sem, contudo, negar as próprias raízes étnicas e culturais (WALSH, 2005, 2010).

Atribui-se a importância em processos de formação de professores considerarmos que o etnocentrismo faz parte de toda trajetória acadêmica dos sujeitos, e que, enquanto professores, tendem a reproduzir essa lógica excludente frente a outros conhecimentos. Essa discussão foi despertada a partir de experiências em atividades desenvolvidas em cursos de formação docente (especificamente em licenciaturas com habilitação em Ciências Biológicas ou Naturais), além das reflexões exteriorizadas pelos professores iniciantes ao se reconhecerem formatados a corresponderem à hegemonia científica do pensar. 
Por isso, as discussões contra hegemônicas influenciaram a organização deste trabalho na perspectiva que ocupa um lugar de fala de priorizar as diferentes racionalidades existentes ao pensar esta estratégia didática.

Mediante essa problematização nestes espaços em que a formação de professores permeia, este artigo ecoa o seguinte questionamento: o que a oficina enquanto estratégia pedagógica provocou nas interações discursivas de licenciandos? Assim, o objetivo principal deste artigo é analisar a intencionalidade da oficina pedagógica como espaço de formação intercultural a partir das interações de futuros professores de ciências e biologia durante o desenvolvimento da estratégia. Este percurso foi realizado com licenciandos do $6^{\circ}$ período da Licenciatura em Ciências Biológicas e do 70 período da graduação de Licenciatura em Educação do Campo (LeCampo).

\section{Procedimentos Metodológicos}

A presente pesquisa apresenta-se de natureza qualitativa pela problematização do dado empírico à luz de abstrações teóricas. Este considera aspectos extraverbais referentes às relações entre os sujeitos participantes e elementos subjetivos dos pesquisadores neste envolvimento investigativo. Bogdan e Biklen (1994) discutem que nessa perspectiva de investigação, o ambiente é fonte direta de dados e o (a) pesquisador(a), por sua vez, por não estar fora do ambiente da pesquisa, desenvolve um trabalho de proximidade, com caráter descritivo evidenciando os detalhes do processo.

O dado empírico emerge de contextos de formações iniciais de professores para o ensino de Ciências Biológicas e Ciências da Natureza, ambos são da mesma instituição pública, porém suas organizações são diferentes sendo que uma é a Licenciatura em Ciências Biológicas e o outra é a Licenciatura em Educação do Campo (LeCampo). O dado empírico foi mobilizado pela sistematização da oficina pedagógica, a qual colocava histórias fictícias com questões que incitavam posicionamentos dos sujeitos participantes sobre aquele contexto. Tais posicionamentos ocupam um lugar enunciativo e, devido a conjuntura em que foram pronunciados, a referência maior é a de posição de professor em formação. Todavia, segundo Volóchinov (BAKHTIN, 2014), além do contexto no qual está, existem símbolos próprios dos indivíduos que ressoam em seus discursos e que remetem a interpretações desses sujeitos que enunciam de diferentes posições sociais. Essas posições enunciativas são atravessadas pela estrutura sociocultural em que o sujeito está inserido, e que, por meio das interações sociais desvelam aspectos subjetivos e objetivos dos sujeitos em suas práticas sociais.

Os discursos estabelecem-se por meio de processos de atribuição de significados e sentidos tensionando a multiplicidade de vozes dos licenciandos que emergem principalmente pela contradição, proporcionando a produção de possíveis frestas discursivas entre esses lugares de enunciação. A hipótese principal é de que a sobreposição da perspectiva científica em detrimento de outras noções de mundo é parte edificante do princípio da racionalidade etnocêntrica (SANTOS, 2007). Pelas tensões enunciativas emergentes ao longo das interações discursivas entre interlocutores há controvérsias que se projetam em cadeias enunciativas gerando a aporia frente aos contrassensos produzidos pelo discurso hegemônico em uma assembleia comunicativa (BHABHA, 1998). São essas aporias que, com a mediação no sentido de manter as interações no espaço/tempo da oficina pedagógica, conduzem a principal aposta desta pesquisa para um movimento discursivo de desnaturalizações de concepções pela desestabilização do etnocentrismo como 
forma de estruturar o pensamento no contexto de formação de professores. A partir das desestabilizações e a inserção de elementos distintos das explicações científicas é possível promover discussões contra hegemônicas como a interculturalidade discutida por Walsh $(2005,2010)$ com premissa de negociação cultural pela horizontalização das relações e não pela categorização e explicações totalizadoras próprias do conhecimento científico ocidental.

\section{Contextos dos Cursos e Sujeitos da Pesquisa}

Os sujeitos participantes, apesar de terem a mesma habilitação para lecionar em ciências e em biologia, são de cursos distintos, os quais se configuram em contextos particulares. O total de participantes nas oficinas foi de 28 licenciandos, sendo 10 da LeCampo e 18 da Biologia. A pesquisa foi pensada nesses contextos a partir do contato durante o estágio e docência (requisito para completar o Mestrado Acadêmico) na LeCampo e, pelas reflexões enquanto egresso do curso de Ciências Biológicas e, ao retorno no mesmo cursos pelo cargo de substituição de docência no ensino superior. Assim, as caracterizações dos cursos, assim como o pensar do desenvolvimento da estratégia, foram pelas leituras dos Projetos Pedagógicos do Curso (PPC's) e pelas vivências nas suas relações, sentindo de fato o impacto da relação estrutural e teórica de forma minuciosa no decorrer das formações iniciais.

A estrutura do curso de licenciatura em Ciências Biológicas é considerada de uma formação regular, com aulas presenciais noturnas todos os dias da semana. O currículo se organiza por semestre e com distribuições de disciplinas específicas da área da Biologia, e as pedagógicas que fazem interface das áreas da educação e ensino de ciências/biologia. Algumas disciplinas possuem carga horária à distância destinada a atividades na educação básica de transposição da disciplina, não sendo incluído ao componente curricular obrigatório de estágio supervisionado. É possível notar que o estímulo dos ingressos da maioria dos alunos foi pelo interesse em áreas de competências do bacharelado, mesmo sendo um curso com possibilidade de habilitação em licenciatura apenas.

O curso de licenciatura em Educação do Campo se construiu em âmbito nacional e também local em um contexto de resistência social, partindo da valorização das comunidades e saberes campesinos ao pensar processos educativos nesses espaços. Por essa premissa, toda estruturação do curso volta-se para atender a esse público, dividindo os semestres do curso em tempo escola (TE) e tempo comunidade (TC). O TE são períodos intensos de atividades na universidade, enquanto que o TC se constitui em atividades realizadas nas comunidades e contextos desses sujeitos. Essa organização é chamada regime de alternância, a qual adapta as atividades no campo com a formação de professores não reforçando a ideia de que a inserção na Universidade retira o sujeito do campo. Por meio dessa relação, tem-se como objetivo também colaborar para construção crítica do sujeito em formação no acesso a Universidade articulada às demandas das realidades do campo, para que sejam pensadas em uma totalidade maior refletindo em mobilizações necessárias (MOLINA; ANTUNES-ROCHA, 2014).

A metodologia do regime de alternância colabora enfatizando a essência da cultura campesina. Isso se dá pela construção e subsistência dos sujeitos do campo com as concepções de usufruir da terra como meio de garantia de vida e o espírito de comunidade que é a raiz de toda resistência, avanços e conquistas para o campo. Assim, essa caracterização de atividades desenvolvidas no campo (a subsistência a partir da produção/agricultura familiar 
que não inclui a exploração exacerbada da terra e o fortalecimento de grupo) constituem o sujeito a partir de leituras de mundo que compreendem uma relação íntima pelas contradições vividas. Sendo assim, a forma como esses sujeitos são recebidos em espaços com metodologias formais de formação dificultaria o comparecimento por sobrepor a essas atividades no campo, elemento importante do modo de vida campesino, e por não reconhecerem ou silenciarem seus saberes, formas de ensinar e aprender (CALDART, 2003). Neste curso, ainda pelas impressões das vivências, é perceptível que o incentivo do ingresso ocorre por duas questões: (1) por uma luta contra a inferiorização do campo como lugar arcaico, possibilitando escolas contextualizadas às necessidades do seu entorno e compreensão da licenciatura e a profissão do professor como o papel principal para articular essas demandas; e, (2) por muitos desses já estarem envolvidos em processos educativos como as Escolas da Família Agrícola (EFAs) e outras escolas, sendo ou não situadas no campo, mas que recebem sujeitos dessas realidades.

\section{A Oficina Pedagógica}

Pelo contato e imersão nos cursos de Licenciatura em Educação do Campo (LeCampo) e Licenciatura em Ciências Biológicas, atividades foram acompanhadas e descritas em um diário de bordo registrando acontecimentos desses contextos que refletiam questões controversas do processo formativo dos professores com habilitação em ciências e biologia. Assim, cinco situações-problemas foram sistematizadas abordando a relação do currículo com questões socioculturais; práticas pedagógicas em estágios supervisionados e a valorização de culturas tradicionais; a diversidade cultural em sala de aula e as controvérsias da hegemonia científica. Essas situações-problema constituíram a primeira parte da oficina pedagógica desenvolvida com 10 alunos da LeCampo e 18 alunos da Ciências Biológicas, sendo que as falas e posicionamentos dos licenciandos foram mediados pelos pesquisadores para que a intencionalidade pedagógica que constitui essa abordagem pudesse ser, de fato, oportunizada.

A primeira situação-problema contava com a controvérsia dos documentos oficiais da educação como os Parâmetros Curriculares Nacionais (PCN) (BRASIL, 1997), Currículo Básico Comum (CBC) (MINAS GERAIS, 2008) e a relação do tema transversal pluralidade cultural nos contextos escolares. Assim, um professor em uma discussão se colocava contra as abordagens dessa pluralidade visto que a escola era urbana e recebendo estudantes de apenas uma cultura. Os licenciandos deveriam se posicionar explicando como interpretavam essa declaração do professor. Na segunda situação, um estagiário demonstrou interesse em realizar suas regências com intuito de recuperar o conhecimento tradicional levando os alunos para comunidades tradicionais. Com esse cenário, os licenciandos deveriam se colocar no lugar do professor regente desta turma, o qual está recebendo o estagiário, e declarar como lidaria com essas questões com os gestores que neste caso, haviam se posicionado contra esse tipo de prática pedagógica.

A terceira situação evidencia a presença de um aluno indígena em sala de aula que traz as questões do direito de autogerenciar sua saúde partindo da ideia dos xamãs, não utilizando da medicina ocidental. Nesse caso, os participantes deveriam abordar como aproximaria e conduziria sua fala durante a aula em que este fato ocorre, além de como propiciaria intervenção dos outros alunos e quais comentários faria sobre este assunto. 
A quarta problemática envolvia a relação dos saberes tradicionais e científicos, com alguns trechos retirados de Baptista e El-Hani (2007) sobre as contradições da relação desses saberes proferidos por estudantes pertencentes ao campo, os licenciados teriam nessa questão que discutir se pode ou não haver relação entre esses saberes. Por último, a quinta questão foi construída ainda em diálogo com a anterior, apresentando uma breve história indígena sobre a relação da quantidade de mosquitos e as fases da lua, após, as indagações para os licenciandos eram sobre como os saberes são validados e aceitos, além de solicitar quesitos mais praticáveis como, por exemplo, formas que eles ligariam esses conhecimentos em uma aula de ciências e se o papel do professor possui esse compromisso. Essas provocações tinham caráter subjetivo evitando que respostas objetivas como sim ou não contemplassem a participação, incentivava-se assim o protagonismo dos licenciandos ao assumir decisões que remetem também às suas subjetividades.

O primeiro momento da oficina foi apresentação da pesquisa e contextualização da temática e de conceitos teóricos que poderiam estar envolvidos com as situações-problema. Essa apresentação ocorreu com espaço para diálogos com os licenciandos e, apesar de apresentar conceitos teóricos não abordados nos cursos, ponderou-se para que não houvesse aliciamento dos discursos no decorrer da atividade. Foi organizada a divisão em pequenos grupos ou duplas, que receberam uma situação-problema para discussão interna e criação de argumentos. Dado um tempo, iniciou-se a assembleia geral de discussão. Cada grupo era responsável por expor seus posicionamentos e os demais participantes poderiam intervir e apresentar seus pontos de vista frente a cada exposição. O momento final contou com reflexões fechando os pontos colocados pelos licenciandos na assembleia geral, de modo que aquela discussão não ficasse presa naquele momento no curso ou disciplina apenas, mas levando para abstrações das relações sociais mais próximas e corriqueiras que interferisse na construção de diferentes significados e atribuições de sentidos na formação do professor de Ciências/Biologia.

A atividade foi audiogravada, transcrita e analisada a partir dos pressupostos teóricos da interculturalidade na interface da teoria pós-colonial de Bhabha (1998) e a teoria do discurso do círculo de Bakthin (BAKTHIN, 2014). O pertencimento teórico foi ilustrado concomitante e no diálogo com a materialidade dos dados analisados, por isso, optouse por não separá-lo em uma seção introdutória. No tratamento dos dados, pseudônimos foram criados evitando a exposição dos participantes, assim, serão mencionados como L1, L2, L3 ... os participantes da licenciatura em Ciências Biológicas e A1, A2, A3... remetendo aos alunos de licenciatura em Educação do Campo, esses serão enumerados pela ordem que aparecerem nas interações.

\section{Resultados e Discussões}

Esta seção tem como propósito a análise das interações oportunizadas pela oficina pedagógica. O olhar dessas análises tem caráter de avaliação e reflexão sobre a oficina pedagógica mediante os contextos em que foi desenvolvida. A avaliação não possui fim taxativo de validação, mas de problematização desta abordagem pedagógica nas intenções formativas que fogem do modelo racionalizado, de cun ho etnocêntrico, de pensar a construção do professor de ciências e biologia. Os dados foram organizados e serão apresentados a partir de três momentos de discussões que sobressaíram no desenvolver das interações. 


\title{
Posicionamentos Performáticos: Parâmetros Científicos que Validam outras Culturas
}

Serão discutidos momentos em que os posicionamentos dos estudantes se revelam de forma performática, em outras palavras, com evidente intenção de corresponder ao discurso que circunda a efetivação da posição de professor. Logo na primeira situação foram problematizados os documentos oficiais Parâmetros Curriculares Nacionais (PCN) (BRASIL, 1997) e Currículo Básico Comum (CBC) do estado de Minas Gerais (MINAS GERAIS, 2008), que regem os aspectos disciplinares e de competências da educação básica. Há uma espécie de julgamento, nas primeiras falas, ao professor que se nega a abordar a pluralidade cultural como se contrariasse uma competência necessária de sua formação. O grupo ressalta o fato de que privar os alunos da diversidade cultural impede de aprender uns com os outros:

\begin{abstract}
É então, vocês perceberam que ele se nega a ter essa competência né... porque ele... ele não busca, né? Então essa competência de lidar com isso deveria ser intrínseca em todos os docentes porque a gente lida com isso o tempo todo em sala de aula. Só que ele considera isso, é... ele considera que na escola dele não tem a diversidade porque não tem alunos da zona rural, não tem alunos de outra origem. Então ele desconsidera a bagagem individual de cada um, a gente percebeu assim. [L4, grifo nosso].

Sim, eles não tem essa cultura e nem nada, mas pode ser que um dia ele precise desse tipo de conhecimento e ele vai ter sido privado disso. Essa foi a conclusão que eu tirei. Mas se for requisito ter um conhecimento prévio... não dá pra gente conhecer a diversidade cultural de cada um. [L5, grifo nosso].
\end{abstract}

A oficina, por estar no contexto de uma disciplina pedagógica do curso de formação de professores tem imbricado os formatos avaliativos de o que é esperado como resposta correta quando uma situação desta é socializada. A correspondência a essa performance certa ressoa um discurso pedagógico padrão que é normatizado em documentos educacionais e reproduzidos em disciplinas pedagógicas acadêmicas. É notável princípios desse discurso pelo destaque de L4 na questão da competência, aspecto muito prezado nas argumentações sobre atitudes procedimentais da atuação docente.

Deste modo, essa estrutura esperada de pensar a construção do professor, já consolidada nos planos de ensino e procedimentos padrões das disciplinas, condiciona o uso de termos pedagógicos como conhecimento prévio, levantado como possível alternativa de reforçar essa competência. No discurso pedagógico, a relação com o conhecimento prévio se dá de forma vertical, pois a prévia vem para reafirmar o distanciamento ao pressuposto científico, que é tomado como verdade a ser ensinada. Assim, tende a articular a substituição de um conhecimento por outro, reforçando a relação hegemônica da ciência podendo inclinar-se para relações comparativas dos conhecimentos (SANTOS, 1987, 2007).

Esse processo perpetua compreensões hegemônicas ou, em outras palavras, é a manutenção do pensamento abissal, que, segundo Santos (2007) caracteriza-se como pensamentos que produzem e radicalizam distinções. O autor ainda aborda que

No campo do conhecimento, o pensamento abissal consiste na concessão do monopólio da distinção universal entre o verdadeiro e o falso à ciência, em detrimento de dois conhecimentos alternativos: a filosofia e a teologia. Esse monopólio está no cerne da disputa epistemológica moderna entre as formas de verdade científicas e não-científicas. (SANTOS, 2007, p. 72). 
A reafirmação da ciência como parâmetro é a maximização de um lugar de poder, os objetos da ciência - personificados em conhecimentos - é disseminado em ambientes de aprendizagem - a escola, a universidade - para que a verdade seja conhecida por todos. Por não fugir da estrutura dos pensamentos colonizadores, utiliza de artefatos enunciativos para valorização dos outros objetos que não são das ciências podendo ser os saberes tradicionais o entremeio que incorpora as relações culturais junto a esse parâmetro personificado em documentos e currículos, resultando em aproximação forçada e destaques temporários.

Na segunda situação o ponto central ficou retido apenas à relação dos documentos oficiais projetados em livros didáticos e a ação do professor: "Ele também poderia pegar aqueles conteúdos e trabalhar fora da sala de aula né, mas continuando com aqueles conteúdos, mas relacionando com o meio em que os alunos estão né, com a vivencia deles?" [A5, grifo nosso]. "E até mesmo as provas que hoje em dia vem para avaliar o desempenho da escola, elas são..." [A4].

A preocupação em corresponder às diretrizes privou a atenção para outros elementos que poderiam ser tensionados e refletidos para além de relacionar à vivência dos alunos. Mesmo que se tenha utilizado de mecanismos que aparentemente buscam romper com as problemáticas da teoria versus prática por meio da relação com as vivências dos alunos, sobressai nessa fala a preocupação de que essa vivência seja assimilada de acordo com o dito nos parâmetros educacionais para obter níveis impostos em provas externas. Não quer dizer, portanto, que esses documentos devam ser ignorados, mas que eles não sejam utilizados como norma que limita as experiências dos alunos ao colocar em comparação com a ciência da escola. Para a mediação, neste caso, é indicado intervir de forma que mobilize os discursos para além dos seus lugares de acomodação, pois sem isso não é possível a formação de frestas na estrutura racional etnocêntrica para a formação de professores provocadas pelas contradições das relações socioculturais.

$\mathrm{Na}$ terceira problemática a discussão pautou-se nas apropriações dos saberes indígenas pela indústria farmacêutica para só após ser validado como verdade:

Eu acho que a gente não precisa fazer uma aula especifica pra trabalhar conhecimento tradicional e conhecimento científico, esses temas vai [sic] surgir. [...] Pra gente poder ali no momento de conversa poder mediar isso, agora assim, a partir lá do CBC, PCN, não tá lá especificando que eu vou ter que trabalhar com isso né. [A10, grifo nosso].

Então é uma questão de métodos? [mediador].

Você tem que dialogar bem pro saber científico e cultural, então é esse momento que você tem que aproveitar. [...] E criar pareceres sem desvalorizar o saber cultural e sem supervalorizar o saber científico. [A1, grifo nosso].

Tanto A10 quanto A1 evidenciaram ainda sua apreensão com as condições estruturais escolares. Mesmo sabendo que isso é um ponto existente e não menos importante, as contradições dessas questões na relação da ação do professor impossibilitam sair do plano performático de pensar essa formação. Reforça-se a ordem discursiva do etnocentrismo como a racionalidade preponderante da abordagem do ensino de ciências na formação de professores. Por outro lado, na LeCampo, muitos argumentos partem da ideia da valorização dos saberes culturais, contudo propõe limite de respeitar os documentos oficiais nesse diálogo cultural com a ciência. Infere-se que tais posicionamentos estão relacionados ao contexto do curso e da relação dos sujeitos com o campo. Porém, nesses discursos demarcados, mesmo 
os sujeitos se colocando por uma visão menos colonizada os argumentos são conduzidos para uma subordinação hegemônica da classe e posição de professor, respaldados pelos documentos educacionais oficiais. As interações, no entanto, ficaram apenas nesse âmbito que por vezes, diminui as projeções concretas de ações para desestabilizar essa monopolização do saber e mesmo com consciência, o pensamento abissal hegemônico da ciência e dos documentos que organizam a mesma no espaço educacional ficam acima das relações íntimas e existenciais à esses sujeitos (FREIRE, 2005; SANTOS, 2007).

É identificado na materialidade discursiva dos dados que no curso de Ciências Biológicas os posicionamentos emergem com mais aderência ao discurso pedagógico por si, diferente da LeCampo que esforça em aproximações dessas relações, mas deixa sobressair o vigor dos parâmetros educacionais para não deixar impressões de defesa da dimensão subjetiva e cultural somente. A manutenção das relações de poder existente nas relações socioculturais é frequentemente associada à naturalização do discurso hegemônico nas atividades cotidianas, personificada aqui no discurso pedagógico. Muitas vezes, no contexto da formação de professores não são percebidas pelos licenciandos, vigorando como ímpeto de aproximação e enquadramento ao discurso científico e não de questioná-lo criticamente. Ao colocar em dúvida os sentidos atribuídos para questões já consolidadas pelo fazer docente, insere-se os estudantes em um processo de tomada de consciência das contradições do discurso pedagógico que, quando percebidas a partir das interações vivenciadas na oficina, possibilitam outros processos de significação sobre a prática docente.

\section{Tensões nas Posições de Enunciação: Frestas do Etnocentrismo no Ensino de Ciências e Formação Docente}

A repercussão da primeira situação-problema é mobilizada na licenciatura em Educação do Campo com interpretações além da performance de uma racionalidade acadêmica apenas: "Uai, mas qual foi a cultura que ele foi colocado, entendeu? Que ele se acha superior, que ele não pode estar falando da outra e interagindo?". [A3, grifo nosso].

No decorrer desta discussão gerada em torno do professor que alega não ter experiência, remete a um acúmulo de conhecimentos transmitidos e que as questões culturais vão além da racionalização etnocêntrica, indicando que a fala do professor o coloca como parte de uma cultura superior. Nesse momento, traz para esse espaço de discussão ecos da hegemonia cultural que privilegia um grupo por ascensão discursiva que coloniza outras formas de pensar, tornando-se um pensamento que sobrepõem outras verdades, tendo apenas uma fidedigna (SANTOS, 2007). O argumento parte de um lugar de fala, ou seja, lugar enunciativo, diferente dos posicionamentos na licenciatura em Ciências Biológicas, posição esta que diz respeito à elementos identitários, de pertencimento a um grupo, vivências e existências que atravessaram esse sujeito e, por isso, ele já se coloca atento às relações de poder e discriminação cultural.

Ao frisar a questão de um licenciando que gostaria de trabalhar no estágio com perspectiva das epistemologias do sul/emergente, a situação dois se desenvolveu na licenciatura em Ciências Biológicas a partir de interações que versaram sobre as diferenças culturais. Contemplando o problema colocado nessa situação, uma fala destacou-se pelos elementos sobre aspectos identitários da posição de futuro professor em tensão com a diferença cultural que ocorre por outras racionalizações e estruturações dos saberes: 
Realização desse tipo de atividade de conhecer culturas novas, enfim... o que isso vai acarretar para os alunos em conteúdo pessoal e científico também. [...] E aí buscar por que isso acontece, porque muitas vezes tem uma raíz lá... na superstição da vovozinha. [...] Porque na verdade nada tá separado, né? Não é porque é Biologia que está totalmente fora da caixinha das questões culturais. [...] Outra coisa que a gente abordou aqui, foi a questão da história da ciência, porque a ciência surge desse quadro mais pragmático né, de fazer não porque eu sei que é assim que se faz, mas fazer por fazer, porque tem que ser assim, porque se precisa daquilo. [L1, grifo nosso].

Quando é defendido o conhecimento de novas culturas e que isso resulta em conteúdos pessoais para os alunos, sem deixar de mencionar o científico, que nesse lugar enunciativo de professor em formação inicial de ciências paira, há nas entrelinhas ideológicas desse papel garantir que a ciência tenha resguardada sua notabilidade. É possível notar todo processo de aproximação feita na fala de L1 que em seu pronunciamento afirma que nada está separado e que a biologia, enquanto símbolo da ciência, não está fora das discussões socioculturais. Este momento traz diluída a controvérsia sociocultural pela diferença cultural e que não soou como uma interpretação reproduzida em uma performance correspondente a âmbitos teóricos, mas que surgiu da inserção e interação, a qual pelos sentidos e significados proferidos e concebidos pelos interlocutores resultou em lacunas oriundas da problematização mediada (BAKHTIN, 2014).

A diferença cultural permite pontes possíveis entre as culturas a partir do dissenso e consenso, saberes adjuntos e adjacentes, que se vinculam momentaneamente no cerne da atividade formativa, como é possível notar nas relações estabelecidas por L1. As interações podem deslocar posições enunciativas antes fixadas permitindo que um mesmo sujeito tome posições ambíguas em determinadas situações (BHABHA, 1998).

O mesmo ocorre na terceira situação-problema, com a discussão de caracterização da ciência e do cientista:

O L3 tinha falado um ponto pra gente analisar o distanciamento que eles veem a ciência né, porque eles veem só o cientista fazendo ciência. [...] A gente pode notar também que pode ter esse relacionamento do conhecimento científico e ancestral mas a função do professor é diminuir esse abismo das palavras que eles usam, como as que os alunos veem, né? [L2, grifo nosso].

Acho que... na parte que ele fala que [...] só o fazer da prática [...] cai na questão da dicotomia entre teoria e prática? Não concordo que só teoria ajuda no conhecimento porque um cara que vê aquilo e depois não vê mais isso, não vai lembrar de nada. [L5, grifo nosso].

Por essa percepção do lugar científico representado pelo cientista, nas interações, os licenciandos levantam as dificuldades e os abismos que ela promove quando interpretada como uma máxima apenas, o que complica a transposição dela na prática educativa. Nesse momento os participantes falam em cima de jargões que são muito problematizados ou colocados como empecilhos na atuação do professor sobre o ensino das ciências, como por exemplo, a questão da teoria e prática. Sobre esses jargões da área de educação, há relação com a produção de sentidos ou divergências desses pelas vivências socioculturais e, sobre isso, Baptista e El-Hani (2007, p. 2) problematizam: "Quando ensinamos ciências, estamos ensinando a cultura de quem? Quais critérios podem ser usados para decidir o que conta e o que não conta como ciência? Como devem ser aplicados esses critérios na construção dos currículos de ciências?". 
Portanto, o emblema teoria-prática poderia ser problematizado por vias interculturais quando os saberes socioculturais não possuem inércia em relação a como o saber científico é posto na formação de professores ou ainda, pelas atividades que subvertem a ordem teoria que diz a prática. Por outro lado, esse jargão foi colocado, nesse momento de discussão, repensando as relações temporárias com os conhecimentos sem que tenha significação para o sujeito e que por isso, são banalizadas.

A interação que segue traz apontamentos interessantes no que diz respeito à discussão anterior:

Então a gente não pode simplesmente descartar o conhecimento popular porque ele é de certa maneira informal. [...] A gente pode pegar esse conhecimento popular e fazer uma desmistificação, por exemplo, no sentido de falar que manga com leite faz mal, mas não é só jogar isso, mas explicar... sabe... tipo... determinados temas que você tá trabalhando... [L6, grifo nosso].

Seria um processo investigativo que resultaria em duas coisas basicamente: investigar o que tem de verdade nesses conhecimentos populares e o que tem de mentira. [L5, grifo nosso].

Quais os critérios para provar o que é verdade e o que é mentira? [mediador].

Esse conhecimento surge a partir da observação. [L3, grifo nosso].

Então, pensando desse jeito, pega uma pessoa que tá no campo e um cientista, né? Se essa pessoa, igual ele falou que ele tinha que fazer, ou seja, ele tava lá todo dia, ele ia e fazia aquilo de novo... não é nada completamente diferente do laboratório, porque você chega no laboratório você tem todos os passos a seguir, tudo direitinho... certos dias tem que ir lá... e isso também acontece. [...] Não é nada diferente, só não está dentro de uma instância que é considerada detentora de saber, né? Porque é uma coisa afastada e de cada um né... mas... cada um é observador né? Se for pensar... [L6, grifo nosso].

Vê-se que, os participantes L6 e L5 na expectativa de propor ações concretas dos aspectos interculturais inferioriza saberes populares, atribuindo a ele uma informalidade. O que se considera informal em saberes populares é sua forma de veiculação social, não sendo por artigos indexados ou livros didáticos, como é formalizado na disseminação da informação científica.

Quando a mediação intervém questionando os critérios para essa desmistificação, L3 defende a questão da observação, que desestabiliza o que foi defendido por L6 e em acordo por parte de L5. Na intenção de salvar as afirmações feitas na primeira fala, mas sem demarcar o desapreço do saber ancestral L6 contra-argumenta trazendo diferentes concepções de ciência e cientista, associando os papeis dessa ação no contexto popular e no contexto acadêmico. A resposta de L6, aparentemente, soa como conciliação do ponto de vista antes defendido por ele e que foi incomodado por $L 3$, no entanto, ainda pode revelar esforços para negociação colonizadora que ao diminuir a diferença, fortalece um discurso hegemônico colonizador de "todos somos iguais" (BHABHA, 1998).

O ponto da racionalidade etnocêntrica sempre reitera na base das discussões dos licenciandos. Os dados nesta segunda seção mostram algumas modificações nos discursos que desencadeia um início de mobilizações nos sujeitos a saírem da rigidez de problematizar pelo viés do etnocentrismo, como ficou bem ilustrado na interação de L6, L5 e L3. É demonstrada atenção diferente, para além da perspectiva performática e, mesmo que ela ainda apareça, inicia explorações para a minúcia do olhar da relação hegemônica que perpassa as relações e discussões socioculturais nos espaços de formação docente. 
Essa minuciosidade de olhar para essas questões proporciona momentos em que a ambivalência das diferentes racionalidades nessa formação profissional do professor seja traduzida em posicionamentos e ações. Estas, por vezes, não são intencionais pelos indivíduos, mas que exterioriza esses conflitos coexistentes nessa posição social exercida.

\section{Mobilização de Saberes Relacionados aos Contextos Socioculturais e Identidades dos Sujeitos: Deslocamentos das Posições Enunciativas}

As ações que se concretizam discursivamente a partir dos exercícios anteriores foram inferidas em alguns momentos desse espaço pedagógico em um processo não ordenatório, ou seja, não foram nas últimas situações a preeminência desses elementos desvelados em deslocamentos dos lugares enunciativos. A receptividade da situação mediante as interações que despertaram e a mediação consciente enfatizando esses elementos mobilizaram essas manifestações.

O desenrolar da terceira problemática da oficina pedagógica, no curso de Ciências Biológicas, sucedeu por meio das somatórias dos exercícios de análise, porém nesse momento, com aspectos mais complexos. Pelo movimento inicial de interpretações provindas de relações com a identidade e ancestralidade individual, frente às respostas e contrapalavras - conceito de Bakthin (2014) que compreende os enunciados como respostas a enunciados precedentes de uma determinada ordem discursiva - nas interações das discussões anteriores, o aprofundamento em pontos primordiais dentro da intencionalidade pedagógica da oficina começa a emergir sem que seja preliminarmente anunciado. A principal intencionalidade aqui foi colaborar para que esses sujeitos deslocassem da fixidez dos seus lugares de fala provocados pelas interações mediadas que os transferiram de uma posição passiva para a agência na disputa discursiva. Nesta situação-problema que envolvia os saberes dos xamãs, algumas medidas iniciais foram anunciadas, respondendo a valorização das culturas: "Pensando no meio acadêmico podia convidar o índio para participar do meio acadêmico e apontar nas pesquisas direcionando erro e se for do interesse dele, porque a gente não sabe ele tem interesse de se enxergar como pesquisado". [L5, grifo nosso].

\footnotetext{
É porque... a gente sempre tá falando em destacar, destacar, destacar e assim... fica parecendo que tem que destacar aquela pessoa porque ela é diferente. Mas não é assim.. eu acho que falta a multiculturalidade no currículo, falta o professor ter a questão multicultural dele em sala de aula, ter a percepção que na sala de aula tem alunos $x, x, x, x, x$. É através disso que ele vai tentar achar soluções ou não para inserir aquele aluno naquele determinado tempo e não ficar aquela coisa de: "ah, agora ele vai falar de plantas medicinais porque ele é indígena e ele vai falar aqui". Não! Ao estar se trabalhando com aquele assunto, vai chegar uma hora que o professor vai perceber esse multicultural e ter ferramentas para se trabalhar com aquilo. Não que seja necessário destacar aquela pessoa porque é diferente porque ela não faz parte daquela cultura que está ali naquela escola. Então é algo bem mais segregativo do que inclusivo. [ $L 6$, grifo nosso].
}

Essa interação ocorreu como contrapalavra a posturas performáticas de caráter comparativista entre ciência e cultura, ou de dissimulação da valorização cultural, tendo esta como pontual, citando em organizar uma semana no ano para as manifestações, por exemplo. A fala de L6 rompe com a linearidade discursiva que vinha construindo ao longo da oficina e se contradiz. Apresenta em seu discurso características contrárias ao multiculturalismo 
diferencialista - conceito discutido por Candau (2008), que parte de uma compreensão que potencializa a partir da assimilação cultural, que é superficial e estereoripada, a diferenciação cultural com respostas de negação e silenciamento das culturas, e de concepções colonizadoras de romantizar e exaltar o outro por ser diferente, partindo de um princípio normativo de uma cultura padronizada, sendo esta a representação de uma cultura normal, bem como anteriormente ele também correspondeu. O que reflete o discurso colonial, nesse contexto de engrandecer culturas estereotipadas, é o silêncio colonial que este discurso produz, isto é, há repetições que perpassam gerações e carregam significados de onde foi produzido, contido em uma história sociocultural - de valorização cultural orientada por parâmetros hegemônicos, sendo também um altruísmo da classe hegemônica - que são silenciados e atravessam os sujeitos e gerações pela linguagem (BHABHA, 1998).

Entendendo que a pauta não é essa, aquela que proporciona a manutenção do discurso colonial no que diz respeito à interculturalidade nos espaços educativos, posicionamentos que rompem com essa reprodução passiva dos discursos cria-se novos rumos nas interações:

Só pra completar o que o colega falou, acho que tem que destacar, discordando do que ele falou, pra mostrar para os alunos que sim ele é diferente e não há problema nisso, acho que é o principal. Mesmo que ele seja diferente que não há nenhum problema dele ser diferente. [L2, grifo nosso].

Pois é, mas é a palavra diferente, acho que ele não precisa ser destacado como diferente. Todo mundo é diferente entre todo mundo, então se for pra parar pra pensar todo mundo é diferente! [L6, grifo nosso].

É que nesse caso a gente pensa numa coisa mais ampla né.., não é o indivíduo, quando a gente pensa em cultura a gente pensa na sociedade em geral. E sobre o dia do índio também que eu queria falar, acho que não tem nem problema ser no dia do índio falar isso, mas desde que não seja mais um dia em que: ah, a gente vai falar isso e fazer uns desenhinhos e pesquisinha. [L2, grifo nosso].

É que assim, eu falei dessa questão de mostrar o índio ali e falar: não, ele faz parte da nossa cultura também, a gente não deixa de ser indígena um pouquinho. [L1, grifo nosso].

O confrontamento com o posicionamento em defesa da não exaltação do diferente, feito por L2, foi proferido em tom diferencialista sobre a cultura indígena, ou seja, maximiza a representação do outro - que é diferente do eu - de forma alegórica e fetichizada (BHABHA, 1998; CANDAU, 2008). Ou ainda poderia ser considerado um multiculturalismo assimilacionista que apenas aceita essa cultura por vias postas de fetichização de sua representação como sendo a única diferente (CANDAU, 2008).

Ao se posicionar deixando ainda mais claro o viés ideológico de seu posicionamento, os enunciados de L6 modificam e incomodam a regularidade discursiva antes instalada. É ilustrado esse movimento de deslocamento discursivo minimamente na fala de L2 que começa a se posicionar evidenciando menos fixidez na cultura indígena, diferente de anteriormente, que se tinha a separação bem definida. A partir destas enunciações L1 levanta a questão ancestral sobre as relações culturais, principalmente a indígena, pela história e pelas relações territoriais do Brasil, começando estabelecer vínculos entre essas culturas, refutando então a delimitação fixa das mesmas. Essas interações evidenciaram a modificação discursiva a partir do reconhecimento dos lugares de fala desses sujeitos, e com as tensões principalmente oportunizadas por L6, os interlocutores se deslocavam da postura multicultural assimilacionista ou diferencialista para reflexões e problematizações próximas de um multiculturalismo interativo ou interculturalidade (CANDAU, 2008; WALSH, 2010). 
O desenvolver dessa situação-problema chegou em questionamentos e reflexões que atenderam a intencionalidade pedagógica da oficina.

Então talvez tentar incorporar ele e fazer ele se sentir o mais natural possível ali e fala: não, você é igual a gente... você não é diferente. você é igual a gente. Pode ser uma coisa muito ruim pra ele também, às vezes ele não quer ser igual a gente, só quer fazer parte da sociedade mas ainda conservando a diferença dele. [L5, grifo nosso]. Mas eu falei no sentido de... não dos outros incorporar ele, mas de reconhecer ele $\boldsymbol{e}$ a contribuição de tudo que ele traz, que ele representa... trouxe pra gente como sociedade, entende? Pra ele, ele sabe. [L1, grifo nosso].

A personificação do deslocamento nesse ponto da discussão foi feito por L5 que ameniza a discordância anterior de L2 e L6, apresentando de forma mais pontual a diferença cultural pela perspectiva intercultural de modo que há a relação pela diferença não sendo por um processo de hierarquização, mas horizontalizando essa relação para além de fetichizações e estereótipos previamente ditados socialmente, apontando para a ecologia de saberes e representações simbólicas provindas deles (BHABHA, 1998; SANTOS, 2007; WALSH, 2010). O desvelar da diferença cultural feita por L5 difere da diversidade cultural por partir das assimetrias instaladas entre as diferentes estruturações dos saberes, práticas e representações simbólicas em que as culturas se configuram, enquanto a diversidade cultural parte de formas de assimilação das culturas a partir de fetichizações de sua representação (AIKENHEAD, 2009; BHABHA, 1998). A linguagem veicula e perpetua os ideais colonizadores dentro de um discurso colonial, mas a enunciação como processo de fortalecimento deste ciclo também é o modo pelo qual pode desestabilizar e perturbar o discurso colonial através da diferença cultural (BHABHA, 1998). Essa fala desestabiliza para uma reinterpretação de L1 sobre seu primeiro posicionamento mediante a problemática revelando elementos que renegam os pressupostos subentendidos anteriormente de supervalorização alegórica.

Esse exercício de L1 pode ser traduzido como a ambivalência do sujeito ocasionado pela relação com o discurso do outro pela lacuna que provoca nesse diálogo. Assim, ele desestabilizou a consistência do posicionamento que vinha sendo defendido causando uma ruptura que se projeta em fronteira entre esses diálogos. As frestas oportunizadas nas interações pelo deslocamento da posição enunciativa e que possibilitou novas interpretações e reflexões sobre a perspectiva cultural não colonizadora, alcança em grandes proporções a intencionalidade pedagógica da oficina que possui princípios contra formas hegemônicas de pensar a formação docente, podendo ser caracterizadas essas frestas e lacunas como momentos interculturais, em que o dissenso e consenso estão sempre em diálogo pela ambivalência dos sujeitos (BHABHA, 1998).

O exercício dos incômodos para o deslocamento do lugar confortável dos lugares falados na licenciatura em Educação do Campo chegou ao ápice rompendo toda estrutura ornamental do discurso de futuro professor. A pesar de consciência e vivência das controvérsias socioculturais de forma próxima, elementos que anteriormente não foram gatilho para essas exteriorizações de ambivalência e identidade dos sujeitos afloraram neste momento da discussão. 
A ciência é uma ferramenta ou uma lente e estudar o fenômenos físicos ou culturais como também os saberes tradicionais é como se fosse uma outra lente que explica também os fenômenos físicos e culturais, que também serve da mesma forma para interpretar esses fenômenos. O que difere é que por meio dos séculos, a lente da ciência ganhou poder hegemônico em que é vista como verdade absoluta e acabada como ferramenta de poder em detrimento ao outro saber o qual se torna de menos valor para a sociedade contemporânea mas deveria ser articulada de uma forma conjunta a qual as duas estão no mesmo nível. [A3, grifo nosso].

Todo saber científico como a maioria dos saberes científicos este é uma base no saber popular, eu vejo isso, só que depois que passa a ser saber científico, aí eles esquecem que partiu de um saber popular. Esse que é o problema. Se você analisar, os remédios de hoje são fabricados a partir de essências a maioria naturais, químicas também, mas a maioria natural. E quando você pegou o principio ativo natural você pegou de uma historia que teve. 'Óh, a cidreira, a erva cidreira que é que eu tenho cidreira lá, ela é calmante', então eles vão começar analisar ele então é um conhecimento popular. [A1, grifo nosso].

Neste trecho, ao usar a metáfora das diferentes lentes de interpretações sobre os fenômenos, provocou em A1 uma ideia de complementaridade com relação à concepção apresentada quando afirma que todo saber científico tem uma base nos saberes populares. Esta indicação foi concebida e exemplificada a partir de uma bagagem de memórias transmitidas pela oralidade de vivências deste sujeito.

Mesmo havendo uma percepção da diferença cultural, o discurso de A3 paira em perspectiva apenas teórica sobre a controvérsia. Quando A1 começa a fazer relações defendendo que todo saber científico tem sua base no saber popular, elementos sobre vivências que quebram a perspectiva exclusivamente teórica e começa a relacionar para dizeres populares que possui significados acordados entre os sujeitos. Essas relações indicam o movimento de cruzamento de fronteiras interculturais pela relação entre concepções epistemológicas diferentes e coexistem na interpretação do sujeito (WALSH, 2010). A afirmação do saber popular ser base para o científico na interpretação da erva cidreira como calmante é um sentido que o licenciando atribuiu naquele momento discursivo. Essas questões e vínculo com vivências tem partida em memórias que são coibidas nas associações e conhecimentos da formação docente.

Esse discurso nasce da controvérsia entre a relação da posição professor com as interpretações de mundo contidas nesse sujeito social e se materializa em um discurso que não corresponde puramente a nenhuma dessas posições, mas ambas. Ao manifestar essa ambivalência, é mais fácil notar a hibridização como a regra, muito bem frisado por L6 e ilustrado nesse posicionamento de $A 1$, que não é uma posição pura que fala apenas a uma construção de pensamento, portanto, um lugar estático de fala. O híbrido não se atém à junção ou associação, mas internalizações de sentidos que se projetam em enunciados, revelando a ambivalência pelos ecos de diferentes cosmovisões que foram apropriadas e significadas dentro da contingência histórica desse sujeito (BHABHA, 1998).

Essa manifestação torna-se um engate para o momento intercultural pelas contradições e ambivalências estruturadas nos enunciados de forma não prevista, pois se tinha no cerne dessa forma de posicionamento elementos identitários e socioculturais mais claros, do que as manifestações performáticas do discurso esperado nesse contexto. O contexto extraverbal em que o discurso foi proferido, dentro de uma formação de professores de ciências, deve responder a outra lógica de pensamento e estrutura de ensino organizado em um currículo próprio. 
Esses elementos são artefatos que podem articular o diálogo entre as culturas pois, pela tensão, deslocou a fixidez dos lugares dos sujeitos para repensá-los considerando as questões identitárias contidas neles neste processo de formação. Assim, o sujeito não abre mão de seus saberes construídos nas relações socioculturais e que constitui sua identidade, mas articula o encontro desses saberes em um processo de interconhecimento, considerando toda ecologia de saberes e cosmovisões existentes no plano en unciativo (BAPTISTA; EL-HANI, 2007; SANTOS, 2007). Esse diálogo, que não é impossibilitado pelo dissenso, pode acontecer por pontos de sutura, pontos de encontro que atendem várias perspectivas de pensamento pelo consenso e dissenso e que, para uma projeção educativa, incluem conceber esse currículo escolar problematizado nas questões socioculturais (AIKENHEAD, 2009).

\section{Considerações Finais}

Analisar as oficinas pedagógicas como estratégia formativa com intencionalidade menos hegemônica e mais local, ou seja, olhando para o sujeito, a exteriorização de sua identidade e suas contradições dentro das múltiplas relações sociais que ele participa, é impulsionada pela mobilização do ato de se posicionar. Por isso, os posicionamentos revelaram potencialidades para a questão intercultural desde as estruturas performáticas até os cruzamentos das fronteiras culturais pela diferença cultural, pois é na tensão desse processo de interações que elementos formativos para pensar o professor vão se configurando.

Ao avaliar como os posicionamentos da LeCampo e a Biologia aparecem revelase comparativos de aspectos específicos da formação de professores de ciências e como se insere uma mediação consciente dessa abordagem. A descrição dessa ferramenta de investigação com finalidades para uma perspectiva intercultural crítica não se configura validada pelo padrão e regularidade das situações-problemas em si, mas pela mediação e interações propiciadas. Sobre as performances, é percebido um o pano de fundo de resposta a essa ordem nos dois contextos de formação. No entanto, a LeCampo trazia uma perspectiva menos colonizada por esses parâmetros científicos, mas que acabava ou se corrompia ao fim para responder a estruturas de documentos oficiais da educação, principalmente.

Em outros momentos, havia a maximização da cultura popular em detrimento da cientifica, subvertendo essa hierarquia, o que não configura a relação intercultural. No exercício desses enunciados que foi tensionado pela mediação e pela própria interação discursiva, a inquietação das situações-problema no contexto de formação projetava a relação dos contextos culturais em que os licenciandos transitavam. Essas tensões possibilitaram frestas estimuladas pelos exercícios de reflexão e socialização das mesmas, que começaram a despertar de premissas multiculturalistas assimilacionistas e diferencialistas para perspectivas interculturais. Essas lacunas e assimetrias chegaram ao desenrolar discursivo que foi o dispositivo chave para fronteiras e cruzamentos interculturais.

As fronteiras ou pontes interculturais revelaram-se a partir da materialidade discursiva em que os elementos emergiram e perpassaram a linearidade temporal a partir de fendas não esperadas ou previstas, enfatizados A1 na personificação do híbrido e L5 na demarcação entre as concepções diferença cultural e diversidade cultural. As interações mediadas geraram mudanças de posicionamentos nos interlocutores desses sujeitos. Ressalta-se que reconhecer o híbrido não é abandonar as fronteiras das diferentes epistemes e não reconhecer as especificidades do conhecimento científico. Identificou-se que o híbrido como regra pressupõe encontrar aspectos interculturais não em sujeitos distintos, mas sim em 
discursos concorrentes. Promover a interação discursiva, em uma situação de maior horizontalidade de relação, é que parece ter possibilitado o reconhecimento de fronteiras culturais por parte dos sujeitos envolvidos na atividade.

Como então, gerar um envolvimento e deslocamento dos sujeitos fora da oficina pedagógica? A racionalização etnocêntrica que paira nas instituições de ensino dificulta essa mudança de olhar dentro de didáticas e estratégias que correspondem a essa hegemonia. Assim, não seria satisfatório pensar a formação inicial intercultural de professores de Ciências e Biologia se primeiramente não houver essa perspectiva bem desenvolvida pelo formador desses professores em formação. Outro ponto importante é a mediação da atividade, pois se esta tiver viés comparativo com o parâmetro científico dificilmente promoverá o deslocamento discursivo necessário.

O fato de comparar não desnaturaliza a soberania científica quando posta em diálogo com outras formas de pensar, além do mais, colabora para o fortalecimento desse pensamento abissal. Os cruzamentos das fronteiras ocorrem para além das identificações, mas a coexistência das diferentes cosmovisões. Há, portanto, várias oportunidades para esse exercício: pelas situações-problema, que permitem um segundo olhar o qual vai além da performance hegemônica. Tais oportunidades desse segundo olhar e de pontes interculturais e cruzamentos interculturais não estão prontos, mas a partir desse formato de repensar questões inerentes à existência desses sujeitos pode-se ocasionar principalmente pelo suporte e direcionamento da mediação.

\section{Agradecimentos}

Agradecemos à Coordenação de Aperfeiçoamento de Pessoal de Nível Superior (CAPES) pelo financiamento concedido a essa pesquisa.

\section{Referências}

AIKENHEAD, G. S. Educação científica para todos. Mangulade: Edições Pedago, 2009.

ANASTASIOU, L. G. C.; ALVES, L. P. Estratégias de ensinagem. In: ANASTASIOU, L. G. C.; ALVES, L. P. (org.). Processos de ensinagem na universidade: pessupostos para as estratégias de trabalho em aula. 3. ed. Joinville: Univille, 2004. p. 67-100.

BAKHTIN, M. (V. N. Voloshinov). Marxismo e filosofia da linguagem: problemas fundamentais do método sociológico na ciência da linguagem. 16. ed. São Paulo: Hucitec, 2014.

BAPTISTA, G. C. S.; EL-HANI, C. N. Diálogo entre modos de conhecer no ensino de biologia: estudo de caso numa escola pública do estado da Bahia. In: ENCONTRO NACIONAL DE PESQUISA EM EDUCAÇÃO EM CIÊNCIAS, 6., 2007, Florianópolis. Anais [...]. Belo Horizonte: Abrapec, 2007.

BHABHA, H. K. O local da cultura. Belo Horizonte: UFMG, 1998.

BOGDAN, R. C.; BIKLEN, S. K. Investigação qualitativa em educação: uma introdução à teoria e aos métodos. Porto: Porto Editora, 1994. 
CALDART, R. A escola do campo em movimento. Currículo Sem Fronteiras, v. 3, n. 1, p. 60-81, 2003.

CANDAU, V. M. Oficinas pedagógicas de direitos humanos. 2. ed. Petrópolis: Vozes, 1995.

CANDAU, V. M. F. Direitos humanos, educação e interculturalidade: as tensões entre igualdade e diferença. Revista Brasileira de Educação, Rio de Janeiro, v. 13, n. 37, p.45-56, 2008.

CHARLOT, B. Formação de professores: a pesquisa e a política educacional. In: PIMENTA, S. G.; GHEDIN, E. (org.). Professor reflexivo no Brasil: gênese e crítica de um conceito. São Paulo: Cortez, 2008. p. 89-110.

FREIRE, P. Pedagogia do oprimido. 42. ed. Rio de Janeiro: Paz e Terra, 2005.

MINAS GERAIS. Secretaria de Educação. Currículo básico comum do ensino fundamental. Belo Horizonte: SE, 2008.

MOLINA, M. C.; ANTUNES-ROCHA, M. I. Educação do campo: história, práticas e desafios no âmbito das políticas de formação de educadores: reflexões sobre o Pronera e o Procampo. Reflexão e Ação, Santa Cruz do Sul, v. 22, n. 2, p. 220-253, 2014.

SANTOS, B. S. Um discurso sobre as ciências. Porto: Afrontamento, 1987.

SANTOS, B. S. Para além do pensamento abissal: das linhas globais a uma ecologia de saberes. Novos Estudos CEBRAP, São Paulo, n. 79, p. 71-94, 2007.

WALSH, C. Interculturalidad, conocimientos y descolonialidad. Signo y Pensamiento, Bogotá, v. 24, n. 46, p. 39-50, 2005.

WALSH, C. Estudios (inter)culturales en clave decolonial. Tabula Rasa, Bogotá, n. 12, p. 209-277, 2010.

\section{ERRATA}

Na página 1, onde se lia:

"Laís de Paula Rédua"

\section{Leia-se:}

"Laís de Souza Rédua"

Ciência \& Educação, Bauru, v. 26, e20001, p. 19, 2020. 